\title{
High-temperature oxidation behavior of SiBN fibers in air
}

\author{
Xin LONG ${ }^{*}$, Zhenyu WU, Changwei SHAO*, Xiaozhou WANG, Yingde WANG \\ Science and Technology on Ceramic Fibers and Composites Laboratory, College of Aerospace Science and \\ Engineering, National University of Defense Technology, Changsha 410073, China
}

Received: December 2, 2020; Revised: February 20, 2021; Accepted: March 5, 2021

(C) The Author(s) 2021.

\begin{abstract}
SiBN fibers are one of the most admirable microwave-transparent reinforced materials for high Mach number aircrafts. Currently, the detailed high-temperature oxidation behavior of SiBN fibers has not been studied yet. In this work, we studied the high-temperature oxidation behavior of SiBN fibers with different boron contents at the temperature range of $1000-1400{ }^{\circ} \mathrm{C}$ in air. SiBN fibers started to be oxidized at $1100{ }^{\circ} \mathrm{C}$, with $\mathrm{Si}_{3} \mathrm{~N}_{4}$ and $\mathrm{BN}$ phase oxidized to $\mathrm{SiO}_{2}$ and $\mathrm{B}_{2} \mathrm{O}_{3}$, respectively. Due to the gasification and the escape of molten $\mathrm{B}_{2} \mathrm{O}_{3}$ at high temperatures, amorphous $\mathrm{SiO}_{2}$ could be remained at the fiber surface. As the fiber further oxidized, the molten $\mathrm{B}_{2} \mathrm{O}_{3}$ at the inside may infiltrate into the fiber interior to react with $\mathrm{Si}_{3} \mathrm{~N}_{4}$, causing the precipitation of hexagonal boron nitride (h-BN) nanoparticles and the formation of $\mathrm{SiO}_{2} / \mathrm{BN}$ layer. Finally, complex oxidation layers with two distinct concentric sublayers accompanied with two transition sublayers could be formed after the oxidizing treatment.
\end{abstract}

Keywords: microwave-transparent; SiBN fibers; high-temperature; oxidation resistance

\section{Introduction}

With the flight speed of aircrafts increasing to a higher Mach number, the aerodynamic heating effect could be more drastic, which caused a huge challenge to the thermal protection of the components in hot end, especially for the radomes that used as the communication windows $[1,2]$. High-temperature microwave-transparent composites (MTCs) are one of the most admirable materials to prepare radomes due to their high mechanical strength, low dielectric constant, high-temperature stability, and excellent oxidation resistance, etc. [3-5]. The reinforced fiber materials are the mainly component of the MTCs, consequently, presenting the great bear on the high-

*Corresponding authors.

E-mail: X. Long, longxin10@nudt.edu.cn;

C.Shao,chwshao@126.com temperature and microwave-transparent properties.

At present, the developed reinforced fibers for preparing MTCs are quartz fibers [6], mullite fibers [7], $\mathrm{Si}_{3} \mathrm{~N}_{4}$ fibers [8], BN fibers [9], and $\mathrm{SiBN}$ fibers [10]. Among them, the application temperatures of quartz fibers, mullite fibers, and $\mathrm{Si}_{3} \mathrm{~N}_{4}$ fibers were 900, 1200, and $1300{ }^{\circ} \mathrm{C}$, respectively. BN fibers could be stable at temperatures higher than $1900{ }^{\circ} \mathrm{C}$, but showing poor oxidation resistance. SiBN fibers combining the outstanding oxidation resistance of $\mathrm{Si}_{3} \mathrm{~N}_{4}$ fibers and the excellent thermal stability of BN fibers, are the most promising wave-transparent reinforcement among these fibers $[10,11]$.

However, the preparation of high-quality SiBN fibers is still a huge challenge due to the complex fabrication process and high sensitivity of precursor $[12,13]$. Thus, almost all of the researches focused on optimizing the fabrication process, whereas the researches 
related to the high-temperature properties of $\mathrm{SiBN}$ fibers are still lacking, especially for their oxidation resistance at high temperatures, which is very important for their actual applications in reinforcing the MTCs that used in high-temperature oxidation atmosphere. To our knowledge, the detailed investigation on the oxidation behavior of SiBN fibers has not been studied yet. Nowadays, only the oxidation behavior of similar ceramic fibers such as $\mathrm{Si}_{3} \mathrm{~N}_{4}$ fibers and $\mathrm{SiBCN}$ fibers have been investigated in detail. For example, $\mathrm{Li}$ et al. [14] found $\mathrm{Si}_{3} \mathrm{~N}_{4}$ fibers formed complex sublayers after oxidizing in air. Cinibulk and Parthasarathy [15] investigated the oxidation behavior of $\mathrm{SiBCN}$ fibers. They also observed the complex sublayers with three distinct concentric layers, each increasing in oxygen concentration from the core to the outer surface. The fibers suffered significant strength degradation after the oxidation treatment. SiBN fibers showed different chemical composition from $\mathrm{Si}_{3} \mathrm{~N}_{4}$ fibers and $\mathrm{SiBCN}$ fibers, thus, should present different oxidation behavior and oxidation layer microstructures.

Recently, continuous SiBN fibers were prepared in large-scale according to our previous work [16]. The obtained SiBN fibers showed excellent high-temperature stability up to $1600{ }^{\circ} \mathrm{C}$ in an inert atmosphere. In this work, these SiBN fibers with different boron contents were treated in the temperature range of 1000 $1400{ }^{\circ} \mathrm{C}$ in air. The oxidation behavior as well as the microstructural evolution and mechanical properties of the SiBN fibers have been discussed through the whole paper.

\section{Experimental}

\section{1 Materials}

SiBN fibers were prepared according to our previous works [16-18]. Four kinds of SiBN fibers were named as SNB-0, SNB-3, SNB-5, and SNB-7 fibers according to their boron contents. The chemical composition and the mechanism properties are listed in Table 1.

\section{2 High-temperature treatments of SiBN fibers in air}

For evaluating the high-temperature oxidation behavior of SiBN fibers with different boron contents in air, a $15 \mathrm{~cm}$ long fiber bundle supported by the firebricks was putted into a muffle furnace. The fibers were then heated with the heating rate of $5{ }^{\circ} \mathrm{C} / \mathrm{min}$ and treated at the target temperatures for $1 \mathrm{~h}$. After the oxidation treatment, all of the SiBN fibers were cooled down to room temperature with a furnace.

\section{3 Characterization}

The carbon content of SiBN fibers was determined by a Horiba carbon/sulfur analyzer EMIA-320V (Horiba, Japan). The oxygen and nitrogen content were measured by a Horiba oxygen/nitrogen analyzer EMIA-820 (Horiba, Japan). The boron content was analyzed by converting the boron into boric acid via solving the samples into molten $\mathrm{NaOH}$, and finally titrating with a standard base solution. The content of silicon in the samples was calculated by the subtraction method in the percentage weight. X-ray photoelectron spectroscopy (XPS) spectra were obtained by using an Escalab 250Xi electron spectrometer (Thermo Scientific, USA) with $\mathrm{Al} \mathrm{K} \alpha$ radiation. X-ray diffraction (XRD) studies were carried out with a Bruker AXS D8 Advance diffractometer (Bruker, Germany) with $\mathrm{Cu} \mathrm{K \alpha}$ radiation $(\lambda=1.54178 \AA)$. The specimens were continuously scanned from $10^{\circ}$ to $80^{\circ}$ at a speed of $0.0167\left({ }^{\circ}\right) / \mathrm{s}$. Secondary ion mass spectrometry (SIMS) was analyzed by TOF-SIMS 5-100 using the $\mathrm{Bi}^{+}$ion with energy of $30 \mathrm{keV}$ as the primary ion beam and $\mathrm{Cs}^{+}$ion with energy of $2 \mathrm{keV}$ as the sputtering ion beam (the sputtering rate was $0.244 \mathrm{~nm} / \mathrm{s}$ that related to $\mathrm{SiO}_{2}$ ). Atomic force microscopy (AFM) images were obtained in non-contact mode using the dimension fastscan system. The morphologies of the samples were examined with a scanning electron microscope (SEM; HITACHI S-4800, Japan). High resolution transmission electron

Table 1 Basic parameters for the chemical and physical properties of SiBN fibers

\begin{tabular}{|c|c|c|c|c|c|c|c|c|}
\hline \multirow{2}{*}{ Fibers } & \multicolumn{5}{|c|}{ Chemical composition (wt $\%$ ) } & \multirow{2}{*}{ Strength $(\mathrm{GPa})$} & \multirow{2}{*}{ Modulus (GPa) } & \multirow{2}{*}{ Diameter $(\mu \mathrm{m})$} \\
\hline & $\mathrm{Si}$ & $\mathrm{B}$ & $\mathrm{N}$ & $\mathrm{C}$ & $\mathrm{O}$ & & & \\
\hline SNB-0 & 60.4 & 0.23 & 36.7 & 0.77 & 2.15 & $1.38 \pm 0.25$ & $137 \pm 5$ & $12.8 \pm 0.6$ \\
\hline SNB-3 & 58.3 & 3.56 & 35.4 & 0.46 & 2.33 & $1.09 \pm 0.21$ & $110 \pm 7$ & $12.9 \pm 0.9$ \\
\hline SNB-5 & 56.1 & 5.14 & 35.8 & 0.58 & 1.60 & $1.47 \pm 0.22$ & $135 \pm 5$ & $12.8 \pm 0.7$ \\
\hline SNB-7 & 56.2 & 6.81 & 34.7 & 0.51 & 1.74 & $1.41 \pm 0.28$ & $123 \pm 6$ & $13.4 \pm 0.7$ \\
\hline
\end{tabular}


microscopy (HR-TEM) images were taken using Titan G2 60-300 with an image corrector. The tensile strength of the $25 \mathrm{~mm}$-long fibers was measured at room temperature using a universal strength machine (Testometric Micro 350, UK) with a load cell of $5 \mathrm{~N}$ and a crosshead speed of $5 \mathrm{~mm} / \mathrm{min}$. Each tensile strength data point was the average of 24 monofilaments.

\section{Results and discussion}

\section{1 Characteristics of SiBN fibers with different boron contents}

Figure 1 shows the SEM micrographs of SiBN fibers with different boron contents. It can be seen that all of the fibers showed a rather smooth surface and dense cross sections, and no obvious defects were detected. However, the rough surface in nanoscale could be distinguished from the three-dimensional AFM images especially for SNB-0 and SNB-3 fibers, with surface roughness $(R a)$ of 3.84 and $4.78 \mathrm{~nm}$, respectively. Whereas SNB-5 and SNB-7 fibers showed a rather lower surface roughness $(R a)$ of 3.25 and $1.85 \mathrm{~nm}$, respectively. These results mean that $\mathrm{SiBN}$ fibers with a higher boron content showed a rather smooth surface, which may be attributed to the higher ceramic yield of pre-ceramic precursors that used to prepare these SiBN fibers.

The microstructure of the obtained SiBN fibers was studied by XRD patterns, as presented in Fig. 2(a). The results showed that all of the fibers were totally amorphous, without diffraction peaks detected. The TEM micrographs and the corresponding selected area electron diffraction (SAED) patterns of SNB-5 fibers also presented the amorphous characteristics of $\mathrm{SiBN}$ fibers (Fig. 2(b)). These experimental data agreed with the results that reported from other research groups $[12,19]$.
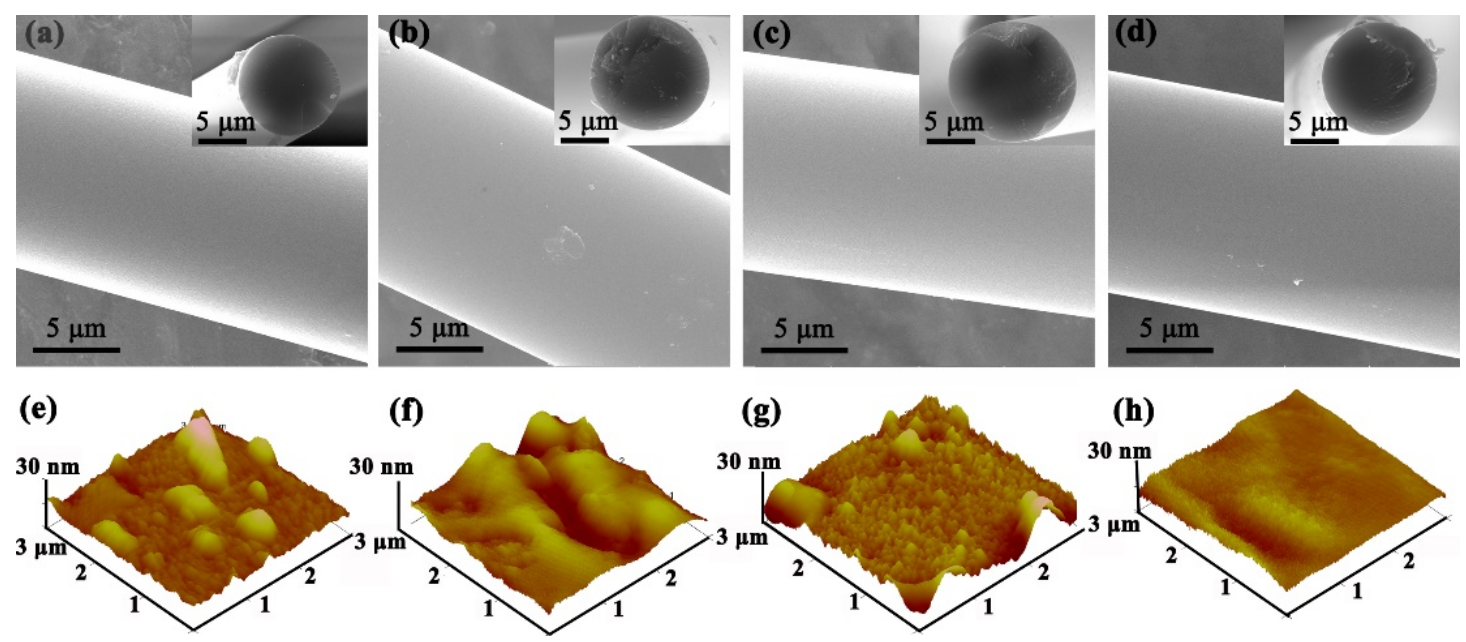

Fig. 1 (a-d) SEM micrographs and (e-h) AFM images of the surface morphologies for the SiBN fibers with different boron contents: (a, e) SNB-0, (b, f) SNB-3, (c, g) SNB-5, and (d, h) SNB-7.
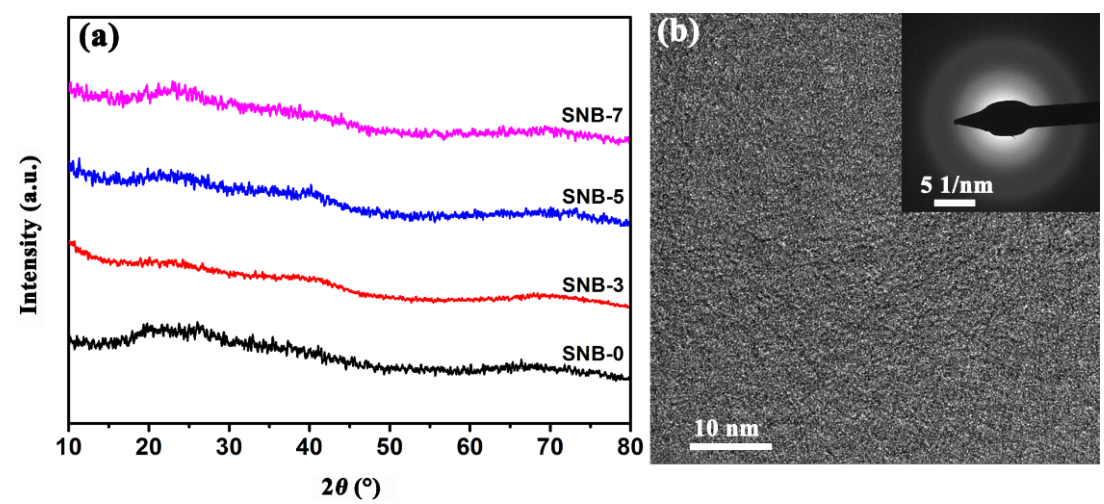

Fig. 2 (a) XRD patterns of SiBN fibers with different boron contents. (b) TEM micrograph and corresponding SAED pattern of SNB-5 fibers. 
For studying the chemical state of SiBN fibers, the fiber surface was analyzed by XPS, as presented in Fig. 3. The XPS spectra showed that the SiBN fibers were mainly consisted of $\mathrm{Si}, \mathrm{B}$, and $\mathrm{N}$ and a small amount of $\mathrm{C}$ and $\mathrm{O}$, which agreed well with the chemical composition analysis in Table 1. For different SiBN fibers, the intensity for the signals of B could be obviously distinguished, indicating different boron contents for the fibers. As shown in Figs. 3(b)-3(d), the XPS spectra peaks of SNB-5 fibers were further analyzed by curve-fitting with Gauss-Lorentz equation. The Si $2 p$ peak could be fitted into two peaks: The strong peak located at $101.8 \mathrm{eV}$ was contributed to the $\mathrm{Si}-\mathrm{N}$ bond in $\mathrm{Si}_{3} \mathrm{~N}_{4}$ phase [20], and the very weak peak located at $100.0 \mathrm{eV}$ was related to the $\mathrm{C}-\mathrm{Si}-\mathrm{N}$ bond in $\mathrm{SiC}_{x} \mathrm{~N}_{y}$ phase. The B 1s peak could be fitted with only one peak that located at $190.8 \mathrm{eV}$, indicating the boron in $\mathrm{SiBN}$ fibers was mainly existed in the form of $\mathrm{B}-\mathrm{N}$ bond in $\mathrm{BN}$ phase [21]. The $\mathrm{N}$ 1s peak could be fitted into two peaks that located at 397.4 and $398.3 \mathrm{eV}$, which were related to $\mathrm{N}-\mathrm{Si}$ bond and $\mathrm{N}-\mathrm{B}$ bond, respectively [22]. Thus, all of the results above indicated that the SiBN fibers were mainly consisted of $\mathrm{Si}_{3} \mathrm{~N}_{4}$ phase and $\mathrm{BN}$ phase. Meanwhile, the $\mathrm{Si}-\mathrm{N}-\mathrm{B}$ networks that distributed between $\mathrm{Si}_{3} \mathrm{~N}_{4}$ phase and $\mathrm{BN}$ phase may also form in the fibers [16].
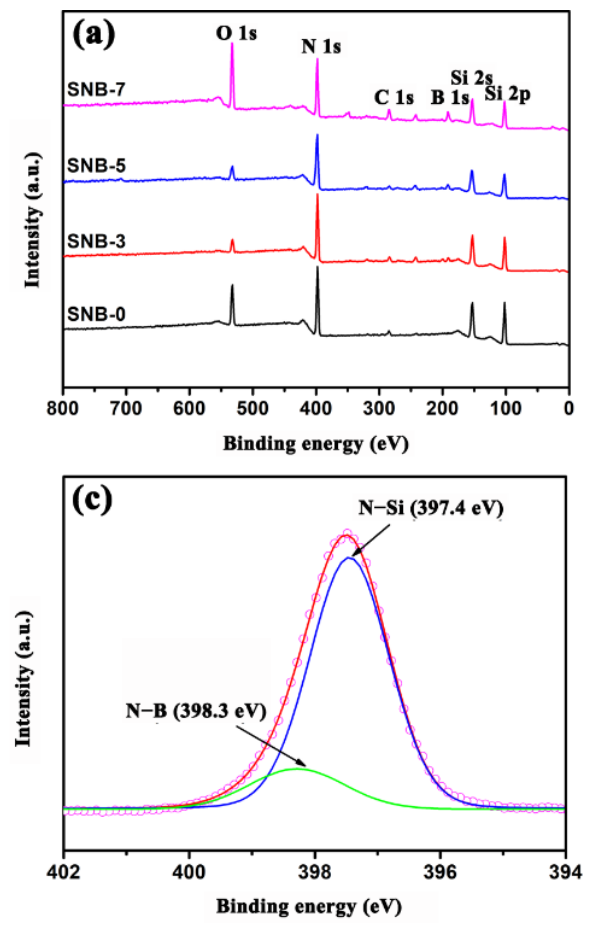

\section{2 Oxidation behavior of SiBN fibers with different boron contents}

According to the previous microstructure and composition analysis, $\mathrm{SiBN}$ fibers were mainly consisted of amorphous $\mathrm{Si}_{3} \mathrm{~N}_{4}, \mathrm{BN}$, and properly $\mathrm{Si}-\mathrm{N}-\mathrm{B}$ networks. These components could be oxidized and formed oxide such as $\mathrm{SiO}_{2}$ and $\mathrm{B}_{2} \mathrm{O}_{3}$, which finally caused the increasing of oxygen content for SiBN fibers after the oxidizing treatment. Table 2 lists the oxygen content for SiBN fibers with different boron contents after oxidizing at the temperature range of 1000-1400 ${ }^{\circ} \mathrm{C}$. When the oxidation temperature was $1000{ }^{\circ} \mathrm{C}$, the oxygen content of SNB-0 and SNB-3 fibers showed almost unchanged, whereas SNB-5 and SNB-7 fibers presented an oxygen content increment of about $2 \mathrm{wt} \%$. These results indicated that the $\mathrm{SiBN}$ fibers with higher boron and $\mathrm{BN}$ content, were easier to be oxidized when the boron content was below $6.81 \mathrm{wt} \%$. As the oxidizing temperature increasing to above $1200{ }^{\circ} \mathrm{C}$, the oxygen content for all of the SiBN fibers increased obviously. As for SNB-5 and SNB-7 fibers, although they were easier to be oxidized, the increasing of oxygen content was slower than SNB-0 and SNB-3 fibers, which may be attributed to the escape of amounts of $\mathrm{B}_{2} \mathrm{O}_{3}$ at high temperatures.
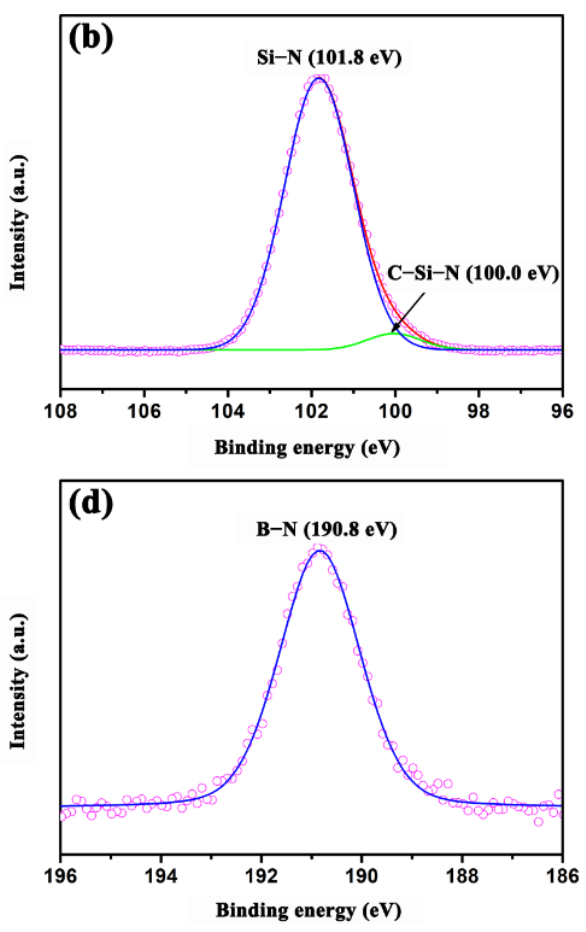

Fig. 3 (a) XPS spectra of SiBN fibers with different boron contents; (b) Si 2p, (c) B 1s, and (d) N 1s spectra of SNB-5 fibers. 
Table 2 Oxygen contents of SiBN fibers after oxidizing at different temperatures in air for $1 \mathrm{~h}$

\begin{tabular}{ccccc}
\hline \multirow{2}{*}{$\begin{array}{c}\text { Temperature } \\
\left({ }^{\circ} \mathrm{C}\right)\end{array}$} & \multicolumn{4}{c}{ Oxygen content (wt\%) } \\
\cline { 2 - 5 } & SNB-0 & SNB-3 & SNB-5 & SNB-7 \\
\hline As received & $2.15(-)^{*}$ & $2.33(-)$ & $1.60(-)$ & $1.74(-)$ \\
1000 & $2.70(0.55)$ & $2.15(-0.18)$ & $3.58(1.98)$ & $4.06(2.32)$ \\
1200 & $3.24(1.09)$ & $3.88(1.55)$ & $4.55(2.95)$ & $4.83(3.09)$ \\
1300 & $4.35(2.20)$ & $5.29(2.96)$ & $5.44(3.84)$ & $5.06(3.32)$ \\
1400 & $6.62(4.47)$ & $6.75(4.42)$ & $6.56(4.96)$ & $6.55(4.81)$ \\
\hline
\end{tabular}

${ }^{*}$ The numbers in the parentheses are the oxygen-content increment that comparing with the as received fibers.

For studying the microstructure evolution of $\mathrm{SiBN}$ fibers after oxidizing treatment, all the fiber surfaces after oxidizing at $1300{ }^{\circ} \mathrm{C}$ for $1 \mathrm{~h}$ were analyzed by XPS, as presented in Fig. 4. The results showed that these fiber surfaces were mainly consisted of $\mathrm{Si}$ and $\mathrm{O}$, whereas the $\mathrm{B}$ and $\mathrm{N}$ were not detected, indicating the escape of boron in the form of $\mathrm{B}_{2} \mathrm{O}_{3}$ gas at high temperatures, which agreed well with the chemical composition analysis. From the fitting curves of Si $2 p$ peak for the oxidized SNB-5 fibers that located at the position of $104.0 \mathrm{eV}$, the chemical composition of the fiber surface was determined to be $\mathrm{SiO}_{2}$, which was formed by the oxidation of $\mathrm{Si}_{3} \mathrm{~N}_{4}$ phase [23].

The microtopographies of SiBN fibers after the oxidizing treatment was observed by SEM. Figure 5 presentes the SEM micrographs of fiber cross section and surface for SiBN fibers with different boron contents after oxidizing at $1300{ }^{\circ} \mathrm{C}$ for $1 \mathrm{~h}$. The results showed that the oxidized SNB-0 fibers presented an oxidation layer of $304 \mathrm{~nm}$, with the formation of obvious cracks between the oxidation layer and fiber interior. The thickness of the oxidation layer for SNB-3 and SNB-5 fibers was 274 and $318 \mathrm{~nm}$, respectively, which was very close to SNB-0 fibers. However, the interface

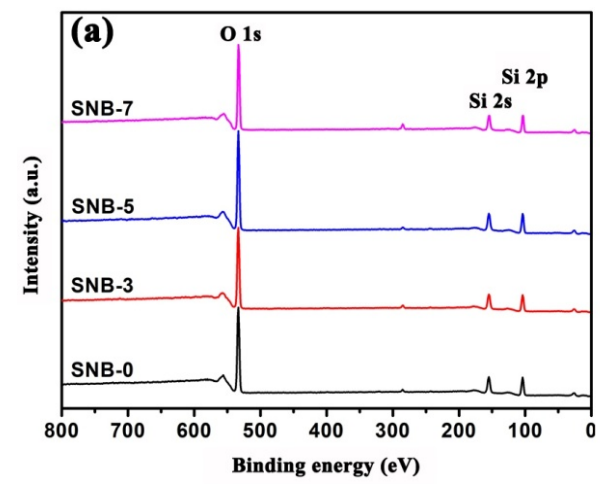

between the oxidation layer and fiber interior showed rather dense, which is different from the interface of SNB-0 fibers. This phenomenon may be attributed to the self-healing effect when part of the molten $\mathrm{B}_{2} \mathrm{O}_{3}$ infiltrated into the oxidation interface. As for SNB-7 fibers, the oxidation layer showed the lowest thickness of $217 \mathrm{~nm}$, which should be caused by the excessive volatilization of $\mathrm{B}_{2} \mathrm{O}_{3}$ gas at high temperatures.

Figure 6 shows the SEM micrographs of SNB-5 fibers after oxidizing at $1000-1400{ }^{\circ} \mathrm{C}$ for $1 \mathrm{~h}$. When the oxidizing temperature reached $1000{ }^{\circ} \mathrm{C}$, no obvious oxidation layer was observed on the fiber cross section. As the oxidizing temperature increased to $1200{ }^{\circ} \mathrm{C}$, the oxidation layer with thickness of about $185 \mathrm{~nm}$ was detected. When the oxidizing temperature reached 1300 and $1400{ }^{\circ} \mathrm{C}$, the thickness of the oxidation layer could increase to 318 and $512 \mathrm{~nm}$, respectively. The increasing of the oxidation layer thickness corresponded with the increasing of the oxygen content. From the SEM micrographs of the fiber surface, it can be seen that SNB-5 fibers remained smooth surface even after oxidizing at $1400{ }^{\circ} \mathrm{C}$, without detecting the obvious cracks that caused by the mismatch of thermal expansion between the oxidation layer and fiber interior. The smooth surface may benefit for fibers to remain rather high mechanical properties after the oxidizing treatment, which will be analyzed in the following discussion.

For analyzing the oxidation process of SiBN fibers, the microstructure of oxidation layer was first investigated by the SIMS. Figure 7 shows the SIMS depth analysis results of the surface for SNB-5 fibers after oxidizing at $1300{ }^{\circ} \mathrm{C}$ for $1 \mathrm{~h}$. According to the intensity of the sputtering oxygen ion signals, the thickness of the oxidation layer for SNB-5 fibers after oxidizing was about $330 \mathrm{~nm}$, which agreed very well with the thickness value that obtained from the SEM

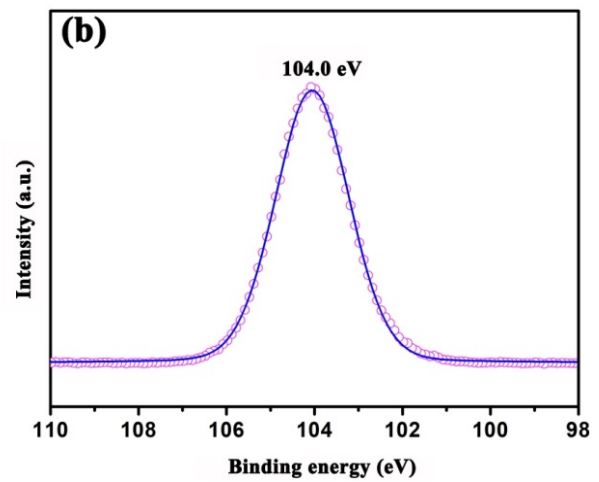

Fig. 4 (a) XPS spectra of SiBN fibers after oxidizing at $1300{ }^{\circ} \mathrm{C}$ in air for $1 \mathrm{~h}$. (b) XPS spectra of Si $2 p$ for the oxidized SNB-5. 


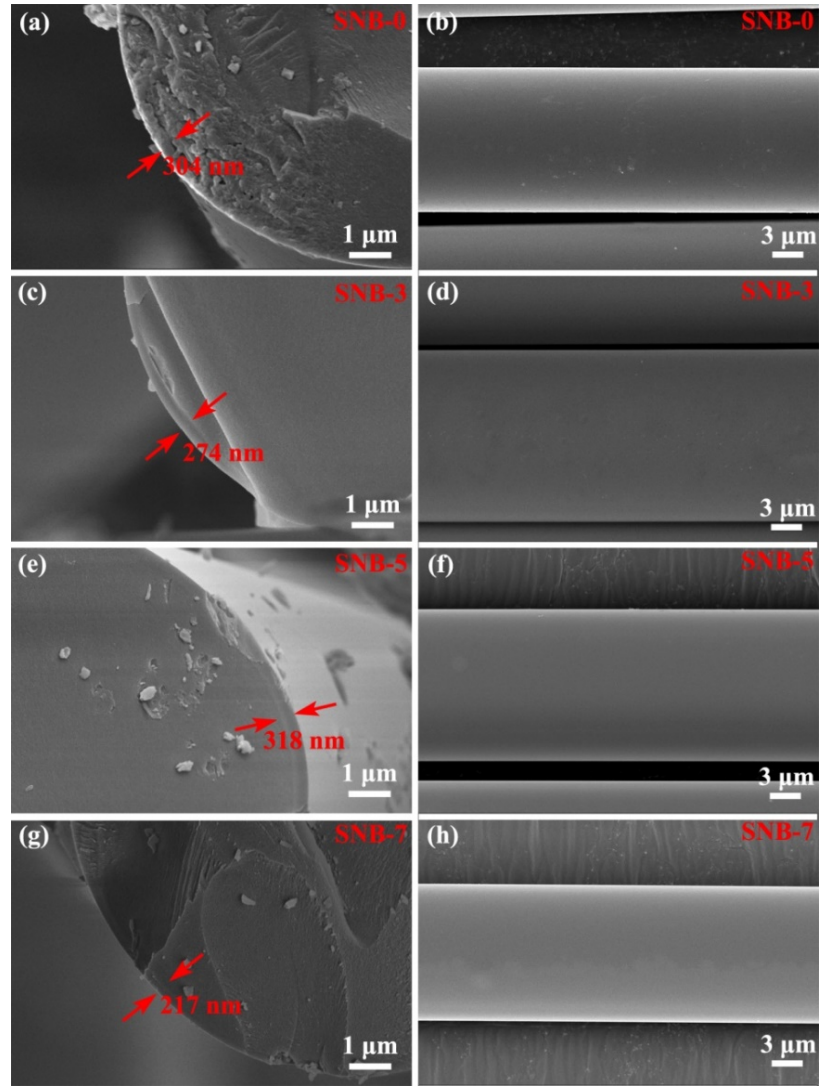

Fig. 5 SEM micrographs for the fiber (a, c, e, g) cross-section and $(b, d, f, h)$ surface of $(a, b)$ SNB-0, $(c, d)$ SNB-3, (e, f) SNB-5, and (g, h) SNB-7 fibers after oxidizing at $1300{ }^{\circ} \mathrm{C}$ in air for $1 \mathrm{~h}$.

micrographs. Meanwhile, the oxidation layer was followed by a $75 \mathrm{~nm}$-depth region with the oxygen ion signals gradually decreasing, which indicated the formation of transitional oxidation layer between the oxidation layer and the fiber interior. By analyzing the intensity of boron ion signals, the oxidation layer could be finely divided into three refined microstructural layers: The outside layer with thickness about $150 \mathrm{~nm}$ showed very weak boron ion signals, and thus this layer was mainly consisted of $\mathrm{SiO}_{2}$, also indicating the escape of boron in the form of $\mathrm{B}_{2} \mathrm{O}_{3}$ gas at the fiber surface. The following layer was a transitional region with a thickness of about $50 \mathrm{~nm}$, where the intensity of boron and nitrogen ion signals increased gradually as the testing depth increasing. Considering the boron content increased along with the nitrogen content, the boron atoms and nitrogen atoms may exist in the form of $\mathrm{BN}$ phase, which could be precipitated from the reduction between $\mathrm{Si}_{3} \mathrm{~N}_{4}$ and the infiltration $\mathrm{B}_{2} \mathrm{O}_{3}$. Previous reports also found the precipitated $\mathrm{BN}$ in the oxidation layer of $\mathrm{SiBCN}$ fibers [15,24]. With the
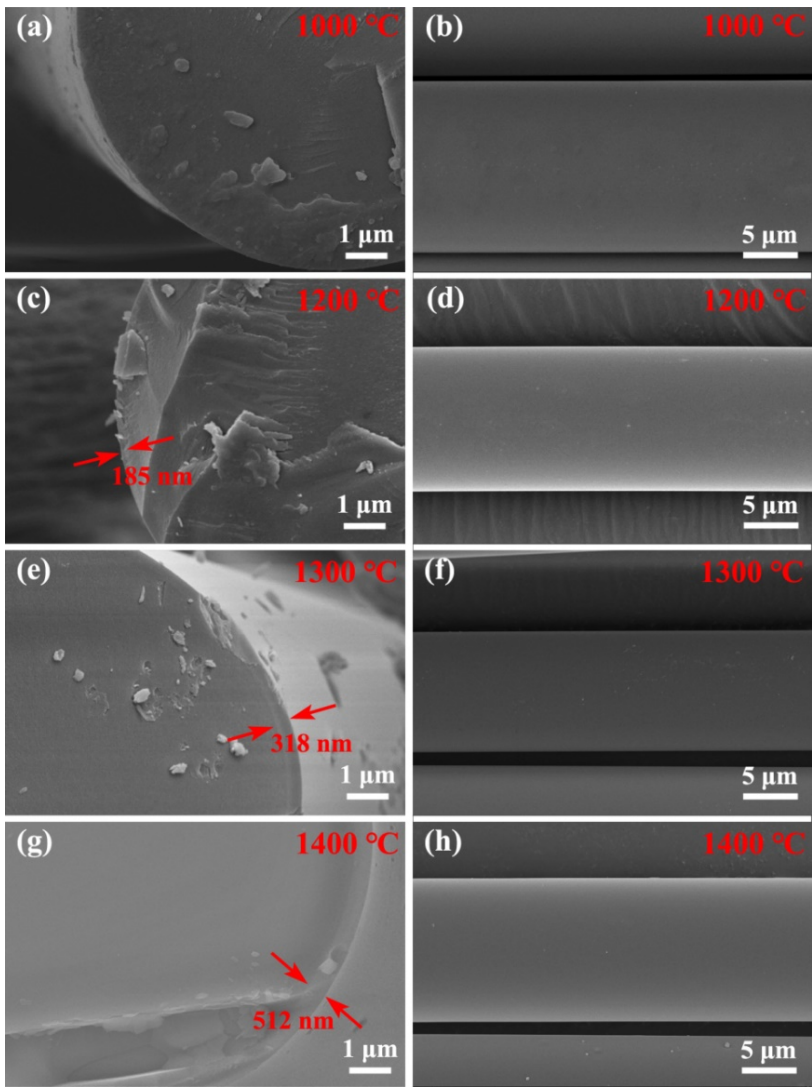

Fig. 6 SEM micrographs for the fiber (a, c, e, g) cross-section and (b, d, f, h) surface of SNB-5 fibers after oxidizing at (a, b) 1000, (c, d) 1200, (e, f) 1300, and (g, h) $1400{ }^{\circ} \mathrm{C}$ in air for $1 \mathrm{~h}$.

depth analysis further increasing, the ion signals of boron, nitrogen, and oxygen remained stable at the layer with the thickness of about $140 \mathrm{~nm}$. This layer presented rather high boron content may consist of more amount of $\mathrm{BN}$ that precipitated from the oxidation layer, which finally formed the $\mathrm{SiO}_{2} / \mathrm{BN}$ layer.

The microstructure of the oxidizing layer was further studied by analyzing the FIB slice of SNB-5 fibers after oxidizing in air at $1300{ }^{\circ} \mathrm{C}$ for $1 \mathrm{~h}$. From the TEM micrograph of the slice (Fig. 8(a)) as well as the enlarged micrograph (Fig. 8(f)), the oxidation layer could be clearly divided into three layers: The outside layer (I) with about $200 \mathrm{~nm}$ thickness was totally amorphous $\mathrm{SiO}_{2}$; the following layer (II) with thickness about $150 \mathrm{~nm}$ showed the precipitation of nanoparticles. The HR-TEM micrographs presented that the nanoparticles were h-BN with interplanar spacing of $0.34 \mathrm{~nm}$. Thus, these results showed the direct evidence for the existence of $\mathrm{SiO}_{2} / \mathrm{BN}$ layer. Meanwhile, a thin interfacial layer (II') with a thickness of about $60 \mathrm{~nm}$ was detected, which was the 
transition region that distributed between the $\mathrm{SiO}_{2} / \mathrm{BN}$ layer and the fiber interior. The formation of three layers in the oxidation layer agreed well with the SIMS results in Fig. 7 (the transition layer between $\mathrm{SiO}_{2}$ and $\mathrm{SiO}_{2} / \mathrm{BN}$ layer was unobvious to be detected in the TEM micrographs).

$$
\begin{gathered}
2 \mathrm{BN}(\mathrm{s})+1.5 \mathrm{O}_{2}(\mathrm{~g})=\mathrm{B}_{2} \mathrm{O}_{3}(\mathrm{l})+\mathrm{N}_{2}(\mathrm{~g}) \\
\mathrm{B}_{2} \mathrm{O}_{3}(\mathrm{l})=\mathrm{B}_{2} \mathrm{O}_{3}(\mathrm{~g}) \\
\mathrm{Si}_{3} \mathrm{~N}_{4}(\mathrm{~s})+3 \mathrm{O}_{2}(\mathrm{~g})=3 \mathrm{SiO}_{2}(\mathrm{~s})+2 \mathrm{~N}_{2}(\mathrm{~g}) \\
2 \mathrm{~B}_{2} \mathrm{O}_{3}(\mathrm{l})+\mathrm{Si}_{3} \mathrm{~N}_{4}(\mathrm{~s})=3 \mathrm{SiO}_{2}(\mathrm{~s})+4 \mathrm{BN}(\mathrm{s})
\end{gathered}
$$

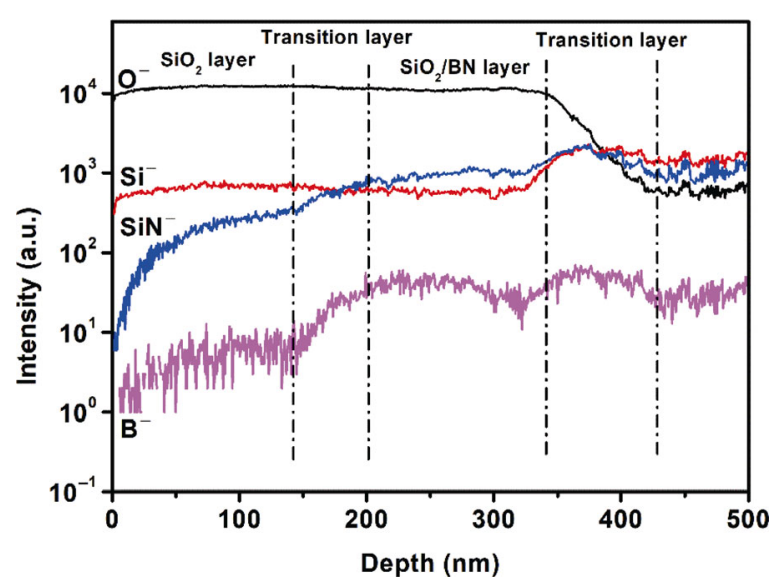

Fig. 7 SIMS depth analysis of surface element content of SNB-5 fibers after oxidizing in air at $1300{ }^{\circ} \mathrm{C}$ for $1 \mathrm{~h}$.
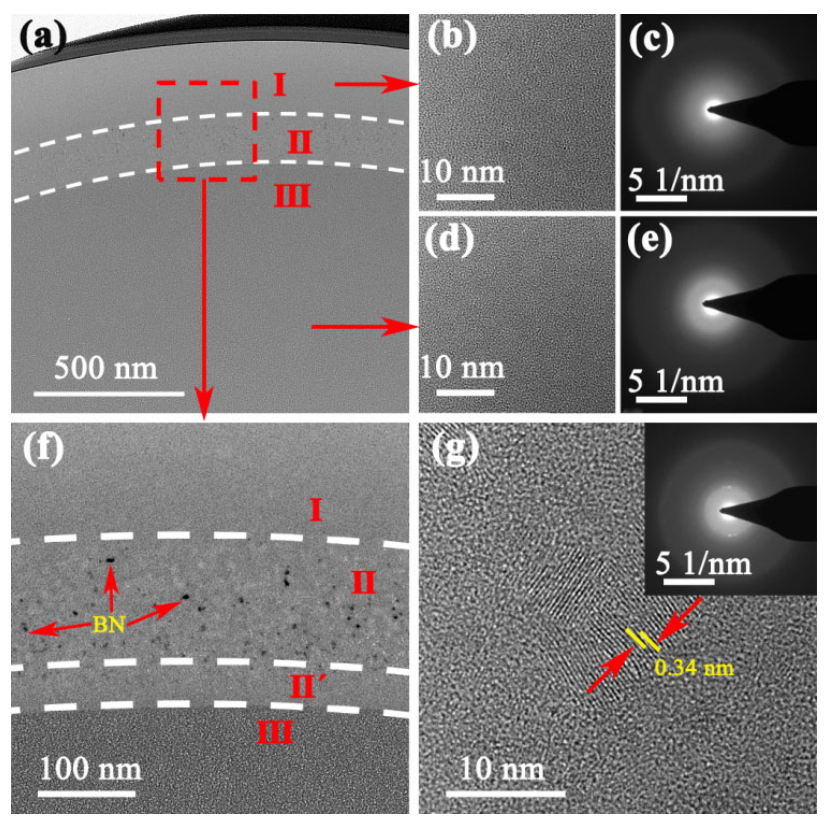

Fig. 8 (a, f) TEM micrographs for the slice of SNB-5 fibers after oxidizing in air at $1300{ }^{\circ} \mathrm{C}$ for $1 \mathrm{~h}$. The HR-TEM micrographs for regions (b) I, (g) II, and (d) III as well as the corresponding SAED patterns for regions (c) I and (e) III.
According to the SIMS and TEM analysis, the microstructure for the oxidation layer of SiBN fibers could be described by the model in Fig. 9(a), in which the oxidation layer could be divided into $\mathrm{SiO}_{2}$ layer and $\mathrm{SiO}_{2} / \mathrm{BN}$ layer. Meanwhile, two different transition layers could also be observed: One was distributed between the $\mathrm{SiO}_{2}$ layer and $\mathrm{SiO}_{2} / \mathrm{BN}$ layer, and the other was formed between the $\mathrm{SiO}_{2} / \mathrm{BN}$ layer and unoxidized fiber interior. Based on the microstructural model of the oxidation layer, the oxidizing process of SiBN fibers could be described as the schematic diagram in Fig. 9(b). When SiBN fibers were oxidized in the air at high temperatures, the $\mathrm{BN}$ and $\mathrm{Si}_{3} \mathrm{~N}_{4}$ phase in fibers could be oxidized to form the oxide such as $\mathrm{B}_{2} \mathrm{O}_{3}$ and $\mathrm{SiO}_{2}$, respectively (Reactions (1) and (3)). In the fiber surface, the molten $\mathrm{B}_{2} \mathrm{O}_{3}$ was easy to escape as gas state at high temperatures (Reaction (2)). Thus, the fiber surface after oxidizing was mainly consisted of remaining $\mathrm{SiO}_{2}$. As the fiber further oxidized, the molten $\mathrm{B}_{2} \mathrm{O}_{3}$ formed inside may infiltrate into the fiber interior to react with $\mathrm{Si}_{3} \mathrm{~N}_{4}$, which finally caused the precipitation of h-BN nanoparticles (Reaction (4)), and consequently formed the $\mathrm{SiO}_{2} / \mathrm{BN}$ layer. All of the layers with different chemical compositions presented the formation of the transition layer due to the diffusion-controlled oxidizing process. The infiltration of molten $\mathrm{B}_{2} \mathrm{O}_{3}$ may act as the self-healing composition, which is beneficial for reducing the cracks in the fibers.

Figure 10 calculates the changes of the standard Gibbs free energy of Reactions (1)-(4) in the temperature range of $1000-2000{ }^{\circ} \mathrm{C}$. The results showed that the standard Gibbs free energy of Reactions (1), (3), and (4) was negative, indicating these reactions could occur at above $1000{ }^{\circ} \mathrm{C}$. As for Reaction (2) that related to the gasification of molten $\mathrm{B}_{2} \mathrm{O}_{3}$, the standard Gibbs free energy was positive. However, when considering the very low partial pressure of $\mathrm{B}_{2} \mathrm{O}_{3}$ in air, Reaction (2) could occur to balance the equilibrium of reaction. Thus, the calculated results confirmed the reactions that mentioned in the oxidation process (Fig. 9(b)).

\section{3 Tensile strength of SiBN fibers after the oxidation tests}

The tensile strength of SiBN fibers after the oxidation treatment is one of the leading indicator to evaluate their high-temperature oxidation resistance. Figure 11(a) presents the tensile strength and the strength retention 
(a)

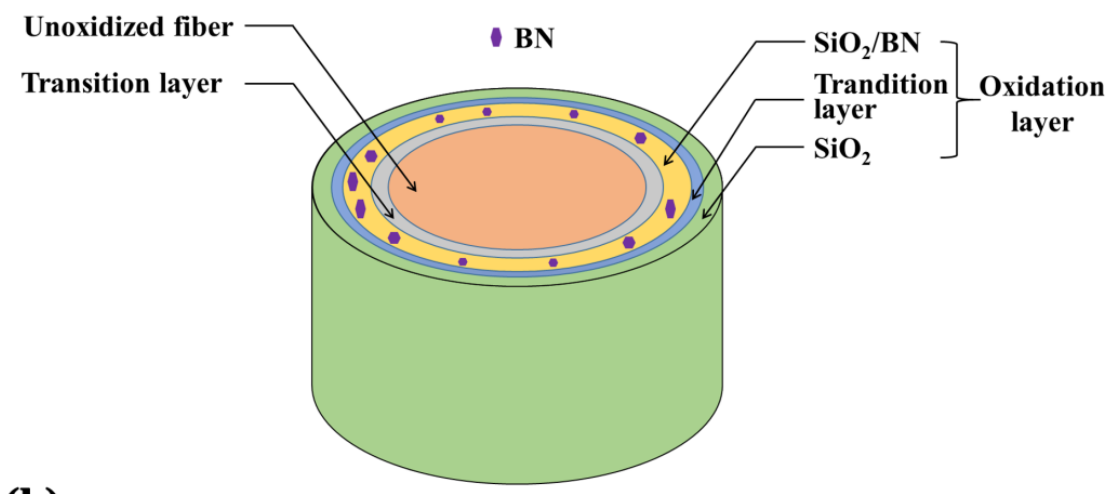

(b)

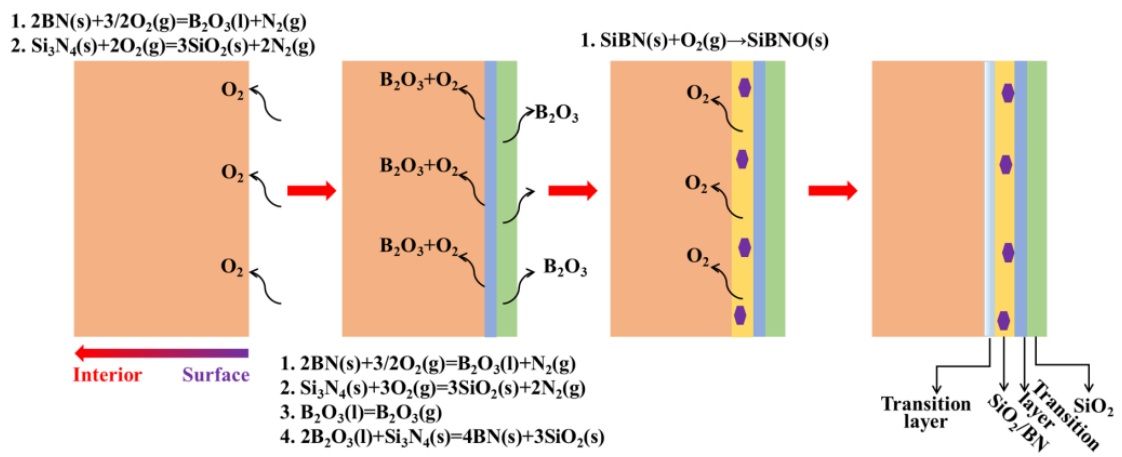

Fig. 9 (a) Microstructure model of the oxidation layer of SiBN fibers after oxidizing in air. (b) Schematic diagram for the oxidation process of $\mathrm{SiBN}$ fibers.

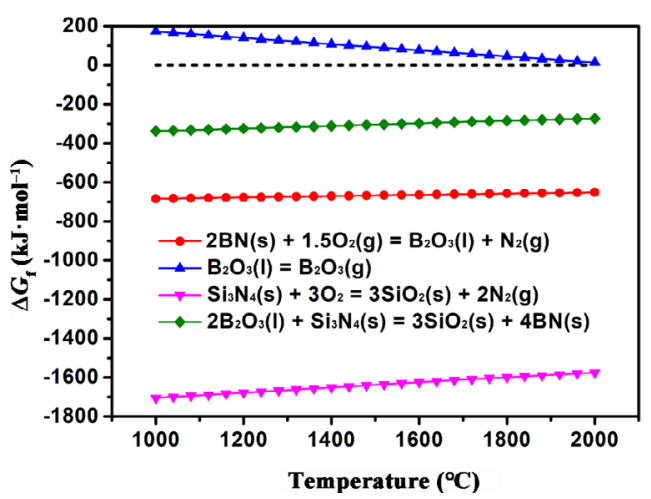

Fig. 10 Calculated Gibbs free energy for Reactions (1)-(4).

of SiBN fibers with different boron contents after oxidizing at $1300{ }^{\circ} \mathrm{C}$ in air for $1 \mathrm{~h}$. As for SNB-0 fibers, the remained tensile strength and strength retention was $0.6 \mathrm{GPa}$ and $44 \%$, respectively, whereas SNB-3, SNB-5, and SNB-7 fibers showed a rather higher tensile strength $(\sim 0.7 \mathrm{GPa})$ and strength retention $(>50 \%)$ after the oxidizing treatment. When comparing with the tensile strength of SNB-0 and SNB-7 fibers after oxidizing at $1000-1400{ }^{\circ} \mathrm{C}$, it can be seen that SNB-7 fibers presented a similar tensile strength when the oxidizing temperature was below

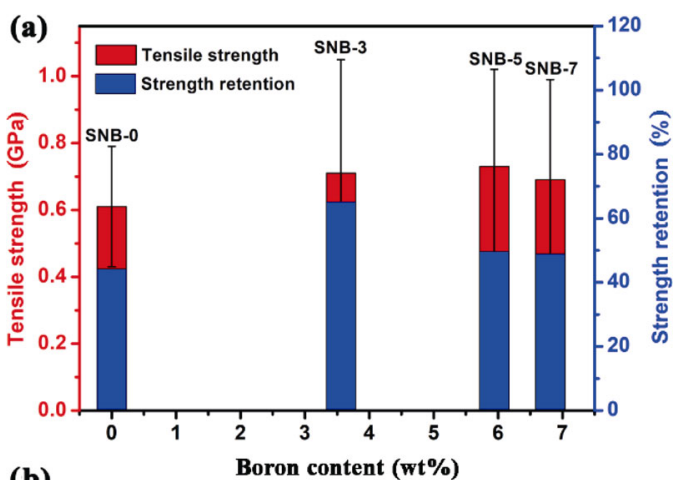

(b)

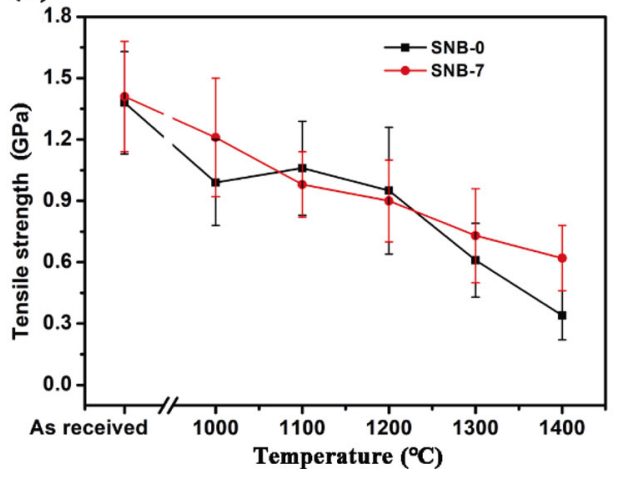

Fig. 11 (a) Tensile strength and tensile strength retention of SiBN fibers with different boron contents after oxidizing at $1300{ }^{\circ} \mathrm{C}$ in air for $1 \mathrm{~h}$. (b) Tensile strength of SNB-0 and SNB-7 after oxidizing at $1000-1400{ }^{\circ} \mathrm{C}$ in air for $1 \mathrm{~h}$. 
$1200{ }^{\circ} \mathrm{C}$, but showed a rather higher tensile strength as the oxidizing temperature went up to 1300 and $1400{ }^{\circ} \mathrm{C}$ (Fig. 11(b)). Thus, although SiBN fibers that consisted of more amounts of $\mathrm{BN}$ phase were easier to be oxidized, they showed enhanced oxidation resistance at high temperatures, which may contribute to the self-healing effects of molten $\mathrm{B}_{2} \mathrm{O}_{3}$.

\section{Conclusions}

In this work, the oxidation behavior of $\mathrm{SiBN}$ fibers with different boron contents was studied after the treatment at the temperature range of $1000-1400{ }^{\circ} \mathrm{C}$ in air. SiBN fibers were mainly consisted of $\mathrm{Si}_{3} \mathrm{~N}_{4}$ and BN phase. After treating at above $1100{ }^{\circ} \mathrm{C}$, the $\mathrm{Si}_{3} \mathrm{~N}_{4}$ and $\mathrm{BN}$ phase in $\mathrm{SiBN}$ fibers started to be oxidized, with the formation of $\mathrm{SiO}_{2}$ and $\mathrm{B}_{2} \mathrm{O}_{3}$, respectively. Meanwhile, at the fiber surface, the molten $\mathrm{B}_{2} \mathrm{O}_{3}$ was easy to escape as gas state at high temperatures, causing the remaining of the $\mathrm{SiO}_{2}$ layer. As the fiber further oxidized, the molten $\mathrm{B}_{2} \mathrm{O}_{3}$ inside may infiltrate into the fiber interior to react with $\mathrm{Si}_{3} \mathrm{~N}_{4}$, causing the precipitation of h-BN nanoparticles and the formation of $\mathrm{SiO}_{2} / \mathrm{BN}$ layer. Finally, complex oxidation layers with two distinct concentric sublayers accompanied with two transition sublayers could be formed after the oxidizing treatment in air. The infiltration of molten $\mathrm{B}_{2} \mathrm{O}_{3}$ may act as the self-healing composition, which is beneficial for reducing the cracks in the fibers.

\section{Acknowledgements}

This work is supported by the National Natural Science Foundation of China (No. 52073304).

\section{References}

[1] Padture NP. Advanced structural ceramics in aerospace propulsion. Nat Mater 2016, 15: 804-809.

[2] Khatavakar N, Balasubramanian K. Composite materials for supersonic aircraft radomes with ameliorated radio frequency transmission-a review. RSC $A d v$ 2016, 6: 6709-6718.

[3] Zou CR, Li B, Wang SQ, et al. Fabrication and high-temperature mechanical properties of $2.5 \mathrm{DSi}_{3} \mathrm{~N}_{4 \mathrm{f}} / \mathrm{BN}$ fiber-reinforced ceramic matrix composite. Mater Des 2016, 92: 335-344.

[4] Cheng ZL, Ye F, Liu YS, et al. Mechanical and dielectric properties of porous and wave-transparent $\mathrm{Si}_{3} \mathrm{~N}_{4}-\mathrm{Si}_{3} \mathrm{~N}_{4}$ composite ceramics fabricated by 3D printing combined with chemical vapor infiltration. $J$ Adv Ceram 2019, 8: 399-407.

[5] Li B, Liu K, Zhang CR, et al. Fabrication and properties of borazine derived boron nitride bonded porous silicon aluminum oxynitride wave-transparent composite. $J$ Eur Ceram Soc 2014, 34: 3591-3595.

[6] Zhao Z, Zhou GX, Yang ZH, et al. Direct ink writing of continuous $\mathrm{SiO}_{2}$ fiber reinforced wave-transparent ceramics. J Adv Ceram 2020, 9: 403-412.

[7] Peters PWM, Daniels B, Clemens F, et al. Mechanical characterisation of mullite-based ceramic matrix composites at test temperatures up to $1200{ }^{\circ}$ C. J Eur Ceram Soc 2000, 20: $531-535$.

[8] Ma X, Liang YY, Qiu HP, et al. Preparation of highperformance $2 \mathrm{D} \mathrm{Si}_{3} \mathrm{~N}_{4 \mathrm{f}} / \mathrm{SiBN}$ ceramic matrix composites by precursor infiltration pyrolysis. IOP Conf Ser: Mater Sci Eng 2019, 678: 012044.

[9] Toury B, Miele P, Cornu D, et al. Boron nitride fibers prepared from symmetric and asymmetric alkylaminoborazines. Adv Funct Mater 2002, 12: 228-234.

[10] Tang Y, Wang J, Li XD, et al. Polymer-derived SiBN fiber for high-temperature structural/functional applications. Chem Eur J 2010, 16: 6458-6462.

[11] Li D, Zhang CR, Li B, et al. Mechanical properties of unidirectional SiBN fiber reinforced boron nitride matrix composites. Mater Lett 2012, 68: 222-224.

[12] Peng YQ, Han KQ, Zhao X, et al. Large-scale preparation of SiBN ceramic fibres from a single source precursor. Ceram Int 2014, 40: 4797-4804.

[13] Baldus HP, Jansen M. Novel high-performance ceramicsamorphous inorganic networks from molecular precursors. Angew Chem Int Ed Engl 1997, 36: 328-343.

[14] Li SW, Li YC, Xiao HR, et al. Oxidation behavior of $\mathrm{Si}_{3} \mathrm{~N}_{4}$ fibers derived from polycarbosilane. Corros Sci 2018, 136: 9-17.

[15] Cinibulk MK, Parthasarathy TA. Characterization of oxidized polymer-derived SiBCN fibers. $J$ Am Ceram Soc 2001, 84: 2197-2202.

[16] Long X, Shao CW, Wang YD. Effects of boron content on the microwave-transparent property and high-temperature stability of continuous SiBN fibers. J Am Ceram Soc 2020, 103: 4436-4444.

[17] Ji XY, Shao CW, Wang H, et al. A simple and efficient method for the synthesis of SiBNC ceramics with different Si/B atomic ratios. Ceram Int 2017, 43: 7469-7476.

[18] Lu L, Feng CX, Song YC. Curing polysilazane fibres by exposure to boron trichloride. J Mater Sci Lett 1998, 17: 481-484.

[19] Liu Y, Peng S, Cui YJ, et al. Fabrication and properties of precursor-derived SiBN ternary ceramic fibers. Mater Des 2017, 128: 150-156.

[20] Hou YB, Li B, Shao CW, et al. Effect of high-temperature annealing in air and $\mathrm{N}_{2}$ atmosphere on the mechanical properties of $\mathrm{Si}_{3} \mathrm{~N}_{4}$ fibers. Mater Sci Eng: A 2018, 724: 
502-508.

[21] Kong J, Wang MJ, Zou JH, et al. Soluble and meltable hyperbranched polyborosilazanes toward high-temperature stable SiBCN ceramics. ACS Appl Mater Interfaces 2015, 7: 6733-6744.

[22] Liu YS, Chai N, Li Z, et al. Effect of deposition temperature on deposition kinetics and mechanism of silicon boron nitride coating deposited from $\mathrm{SiCl}_{4}-\mathrm{BCl}_{3}-$ $\mathrm{NH}_{3}-\mathrm{H}_{2}-\mathrm{Ar}$ mixture using low pressure chemical vapor deposition. Surf Coat Technol 2015, 261: 295-303.

[23] Li DX, Yang ZH, Jia DC, et al. High-temperature oxidation behavior of dense SiBCN monoliths: Carbon-content dependent oxidation structure, kinetics and mechanisms. Corros Sci 2017, 124: 103-120.

[24] Ji XY, Wang SS, Shao CW, et al. High-temperature corrosion behavior of SiBCN fibers for aerospace applications. ACS
Appl Mater Interfaces 2018, 10: 19712-19720.

Open Access This article is licensed under a Creative Commons Attribution 4.0 International License, which permits use, sharing, adaptation, distribution and reproduction in any medium or format, as long as you give appropriate credit to the original author(s) and the source, provide a link to the Creative Commons licence, and indicate if changes were made.

The images or other third party material in this article are included in the article's Creative Commons licence, unless indicated otherwise in a credit line to the material. If material is not included in the article's Creative Commons licence and your intended use is not permitted by statutory regulation or exceeds the permitted use, you will need to obtain permission directly from the copyright holder.

To view a copy of this licence, visit http://creativecommons. org/licenses/by/4.0/. 